\title{
Ten Years of the Institue for Research in School Education
}

\author{
Tomáš Janík, Petr Najvar, Marie Doskočilová
}

In 2013, the Institute for Research in School Education (IRSE), Faculty of Education, Masaryk University take the opportunity to look back at the ten years that have passed since its establishment. IRSE was set up in 2003 as a new department at Masaryk University's Faculty of Education whose purpose is to initiate and support research activities of not only its own members but also all the other faculty staff. This report is one of the ways of looking back. We introduce IRSE and summarise some of its activities and achievements in its first decade.

\section{Introducing IRSE}

IRSE's goal has been to promote research in school education in broader socio-cultural contexts. The Institute's core areas of interest are in the educational conditions, environments, actors, aims, contents, processes and outcomes at primary and secondary school levels.

IRSE's mission (summarised in the motto better education through research) is to develop both in-depth knowledge of the educational reality in schools and elaboration of theoretical base for improving their practice. In order to reach these goals the members of IRSE employ a wide range of research approaches: theoretical and empirical as well as interdisciplinary and comparative. Besides the quantitative and qualitative methodology the mixed-method design is employed.

The focus of IRSE also lies on the pedagogical methodology, especially the relation between the theory and practice, general didactics and subject didactics, mixed methods, video-based methodology, comparative methodology in the research on curriculum and the contrastive approaches in the research on teacher education.

IRSE develops expert reports and evaluation studies for the Czech Republic's Ministry of Education and its organisations. The research findings are publicly discussed as the Institute's ambition is to give voice to research community.

IRSE participates in the doctoral study in Educational sciences programme at the Faculty of Education by supervising doctoral students and prospective applicants. The Institute offers lectures, seminars and workshops on research methodology and subject didactics, it also hosts visiting scholars from the Czech Republic and abroad. 
82 A special book series Educational Research in Theory and Practice (counting more than twenty publications) was introduced in order to present research findings to public.

IRSE's aim is to undertake projects which investigate the three general pedagogical areas of 1) curriculum, 2) teaching and learning, and 3) teacher education.

\section{1) Focusing on the aims and contents of school education (curriculum)}

IRSE investigates the processes of designing, implementation, realisation, evaluation and revision of curricular documents, textbooks, etc. The focus lies on relations between theory and practice, curricular policies and educational practice with regard to general didactics and subject didactics.

\section{Research on textbooks and other curricular documents}

Curriculum is viewed as a complex of issues concerned with questions why, who, in what, how, when, under what conditions and with what expected effects to educate.

The aim of IRSE is predominantly:

- to generate knowledge of curriculum, to inform theory and practice in particular;

- to develop and optimise methods of empirical investigation into curricular documents, especially textbooks including the broader context of their development, authorisation, use, assessment, etc.;

- to provide theoretical and methodological support and publishing opportunities to beginning as well as senior researchers in the area of curriculum research;

- to organise regular conferences and seminars which support establishing and expanding the research community dealing with the issues of curriculum.

The purpose of the Institute's ongoing activity is to develop curricular research and its methodology. We concentrate on the methodology of developing aims and content of school education and on implementation of curricular reforms, especially on outlining the curricular processes and forms as well as their mutual interaction. In addition, historical-comparative and content analyses of the curriculum are dealt with in a number of dissertation theses.

One of the important areas focused on by IRSE is the research on textbooks. Textbooks may be viewed either as a product, curricular project or a medium in a narrow sense, or from the perspective of processes of their development, use, assessment, etc. in a broad sense. Furthermore, the issue of textbook research methodology is important to us as many questions concerning data objectivity and reliability remain unanswered in this research area. The findings available are often based on intuition or long-term pedagogical experience. Although such assumptions may be correct, IRSE strives to verify them empirically.

IRSE participated in the Kvalitní škola (Quality school) research whose concern was to monitor the processes and assessment of the curricular reform. The aim of the research was to describe, analyse and evaluate the Framework Education 
Programme implementation, the School Education Programme development and its realisation. Factors influencing those processes were identified as well as roles which the framework and school programmes play on the levels of curricular planning, work with educational aims and content. Relevant data relating to the qualitative changes on the school level, curriculum and lessons were gathered from interviews with coordinators of school programmes (phase 1), from questionnaires (representative sample of grammar schools, phase 2), case studies of the processes of the curriculum development (phase 3), video studies focusing on curriculum realisation (phase 4) and from expert inquiry (phase 5).

\section{2) Focusing on classroom processes}

IRSE develops a video-based methodology of teaching and learning as they occur in classrooms and conducts research into various aspects of teaching and learning in different school subjects. Through investigating both the overlap between the subject-specific issues and the inter-subject similarities and differences, the aim is to develop a concept of transdisciplinary didactics. The ultimate concept is quality of instruction.

Video Study: classroom research in Czech schools (2004-2012)

Since 2004, IRSE has been conducting a series of inquiries into classroom processes in different subjects in primary and lower-secondary schools. The IRSE Video Study is an umbrella label for different video-study projects:

- Video Study of Physics (2004),

- Video Study of Geography (2005),

- Video Study of English (2007),

- Video Study of Physical Education (2007),

- Video Study of Primary Education (2011),

- Video Study of German (2012).

The ultimate goal of the individual video-study projects is to explore the processes of teaching and learning in different school subjects at primary and lower-secondary school levels. The aim is to document, describe and analyse the reality of everyday teaching in different school subjects and provide a comparative perspective. Such comparison will enable us to gain an in-depth knowledge of the differences arising from the different content-specific nature of the school subjects.

The aims of the video study are:

- to contribute to establishing basic knowledge of teaching and learning processes that take place in different subjects at primary and lower-secondary school levels, and to provide for an in-depth understanding of such processes in transdisciplinary perspective;

- to elaborate on methodology for investigating classroom processes with regard to current topics, such as competencies and the ways to enhance them 
84 - to use the video-recordings in teacher education withthe respective teachers' consents.

Each lesson is videotaped using the standardised procedure with two video cameras. The student camera captures the activity of most students from the blackboard-side corner of the classroom, and the teacher camera captures the teacher's activity. At the primary level, the sample includes 10 lessons of English as a foreign langauge and 10 lessons of primary science; at the lower-secondary level, the sample includes videotapes of 62 lessons of physics, 50 lessons of geography, 58 lessons of physical education, 79 lessons of English as a foreign language and 28 lesson of German as a foreign language.

\section{3) Focusing on teacher education}

IRSE focuses on teacher training and professionalisation, the processes of the shift from novice teachers to expert teachers, contributes to their support and analyses the role of contextual variables in such processes. Teacher professional competence is monitored in areas of teacher thinking and knowledge, special focus lies on developing pedagogical content knowledge.

\section{Using videos in teacher education (video web)}

IRSE develops a videobased e-learning environment. The IRSE Video Study started the development of an e-learning environment for future teachers. The IRSE Video Web refers to learning environment involving video recordings of lessons and related set of questions and tasks to be answered or solved by future teachers. The aim of the IRSE Video Web is to foster students' professional vision which helps them prepare for their own teaching.

The IRSE Video Web has two general functions. 1) As an instrument for developing students' professional vision the video web functions as a guide for future teachers to explore different pedagogical situations, to structure their thinking, to help students describe, interpret, clarify and assess the observed situations, all leading to enhancing their professional vision. 2) As a diagnostic instrument for assessing future teachers' reflective competence, The IRSE Video Web generates research data (e.g. the answers to questions, rating of observed situations) which enables the researchers to analyse student's thinking about the observed situations.

In order to develop the video web a research group has been established at the Faculty of Education, MU, represented by experts in didactics of the subjects which were included in the IRSE Video Study and the TIMSS 1999 Video Study - physics, geography, chemistry, biology, physical education and English. The experts in didactics sought video sequences exemplifying particular subject matters and developed a set of questions and tasks for students. The video web cooperated with experts in information technology who loaded the video clips into the MU Information system, enabling their access to the registered students. 


\section{Management structure of IRSE}

The head of the Institute formulates IRSE's research programme in cooperation with the management of the Faculty of Education MU (bottom-up) and with the heads of research groups (top-down). The head also supervises activities of the research groups and publications.

The heads of research groups are responsible for the strategy and planning in their thematic areas (curriculum, teaching and learning, teacher education), prepare project proposals in compliance with IRSE's research programme. The heads of research groups are autonomous researchers, presenters of the projects and main authors of project outcomes.

The members of research groups cooperate on carrying out the project tasks. They become co-authors of the project outcomes. The members of the research teams are staff members and doctoral students of the Faculty of Education MU as well as guest experts.

\section{Current projects}

Following its research agenda, IRSE realises and participates in various research projects granted by the Czech Science Foundation, Masaryk University and other bodies. Some of the projects are listed below with a short description of their aims.

Exploring professional vision and its development through video-based analysis (from the perspective of teachers of English as a foreign language) - GA ČR GA13-21961S

The project draws on current debates of teacher professionalization and quality in education and aims to research a relatively new concept of teachers' professional vision. Professional vision, linked to professional knowledge and professional action, offers a possibility to re-conceptualize teacher professionalism. It has two components - noticing (what teachers attend to) and knowledge-based reasoning (the process of making sense of a situation). In the project we focus on teachers of English as a foreign language (EFL) and aim to (1) describe the nature of professional vision of EFL teachers; (2) explore the influence of participation in a videoclub (collaborative video-based analysis) on teachers' professional vision and explore its acceptance among participating teachers, (3) explore the relationship between professional vision, professional knowledge and professional action. Research methods including qualitative content analysis of teachers' comments on video sequences and of teachers' self-reports, acceptance questionnaire and video study will be used to achieve the aims. 
86 Opportunities to develop problem solving competence in textbooks and in the classroom - GA ČR GPP407/12/P059

Ongoing educational reforms in the Czech Republic strive to introduce new culture of learning and instruction. Together with new culture of learning and instruction, new theoretical concepts are introduced such as key competences which represent the highest aim of education in many educational systems around the world, including the Czech Republic. There is a lack of data that could provide a comprehensive picture of the curriculum materials as well as of the schooling processes as they occur in schools and classrooms; that could provide us with information about the implementation of educational reform. We suppose that questions and tasks can be the most influential and approachable features in the process of implementing new ideas, aims and objectives. In the proposed research we focus on problem-solving competence, as an example of a key competence. The purpose of the research is to examine and describe the nature and qualities of questions and tasks in geography textbooks and instruction with regard to the development of problem solving competence.

Foreign language learning strategies and achievement: Analysis of strategy clusters and sequences - GA ČR GAP407/12/0432

The project is based on an analysis of problems of foreign language learning and instruction in the Czech Republic. Many pupils do not reach the expected language level even after many years of learning. The reason is not only the quality of instruction but also the learning strategies of pupils. More than two thirds of pupils reported not to be sure of how to learn and showed deficiencies in learning skills and strategy use. The project is based on the current state of the art of learning strategies which shows that they do not exist separately but in sequences and clusters that have to be described and analysed in terms of their orchestration and quality of use. The aim of the project is 1 ) to introduce the concept of strategy sequences and clusters as a theoretical construct, 2) to point out the typical sequences and clusters of foreign language learning strategies and their relation to achievement in language situations and tasks, 3) to specify the relation of strategies and achievement in foreign language at the end of lower secondary (i.e. compulsory) education.

\section{Quality of curriculum and instruction in school education - GA ČR P407/11/0262}

The project is based on an analysis of problems in school education which were identified by the Czech educational research in 2001-2008. A number of the problems are related to the quality of curriculum and instruction. The two concepts are often mentioned in political slogans, however, they have not yet been established as scientific constructs. The aim of the project is to (1) introduce the concepts of quality of curriculum and instruction as theoretical constructs, (2) develop instruments for their empirical research, and (3) carry out research studies on the quality of curriculum and instruction in different school subjects (languages, maths and science, social sciences, aesthetics and sport). Three methodological principles are applied: 
(A) systematic approach, (B) content-process-oriented approach, (C) connecting the domain-specific and the domain-general perspectives - the quality of curriculum and instruction is primarily investigated from the point of view of field didactics, but building on a cross-curricular comparison, it will achieve generalizations across the subjects concerned.

An expert teacher: his/hercharacteristics and the determinants of his/her professional development (in the context of foreign language teaching) - GA ČR P407/11/0234

The ongoing discussion concerning the quality in education concurrently addresses one of its central challenges - the professionalisation of a teacher. The project aims to shed more light on the concept of expertise in the teaching profession. Firstly, an extensive survey of theoretical and research studies of expertise in the teaching profession will be carried out, then on the basis of its outcomes and considering the specifics of the Czech cultural context the project is going to develop, pilot and verify methods for the core of the project, i.e. research into the nature of teacher expertise in the first phase and research into the processes and conditions of expertise development and maintenance in the next phase. The results may provide information crucial for reshaping and transforming pre-graduate as well as further teacher education, for setting the standards of quality in teaching and, last but not least, for raising the status of the teaching profession.

Pupils' skills in biology, geography and chemistry: research into planned, realized and achieved curriculum in the implementation phase of curricular reform - GA ČR 407/ $10 / 0514$

The main aim is to propose a structured and linked system of pupils' skills, which should be acquired in geography, biology and chemistry in primary and secondary schools on the basis of results of a multi-level analysis of skills in terms of intended, realized and acquired curriculum.

\section{Projects realised in the past}

Since 2003, IRSE has realised or participated in various projects, some of which are listed below with a short description of their aims.

Research Centre on Schooling - LC 06046 (2006-2011)

In general, the project aimed to gain a new theoretical knowledge concerning structures, aims, contents and processes of schooling under the changing economic, social and cultural conditions of the society and to analyse consequences for educational policies and school practices. More specifically, the project aimed to analyse the process of transformation of education systems in central Europe and other european countries, to analyse the implementation of the principle of equity in education, 
88 to analyse stakeholders' demands on education, to develop a theoretical model of curriculum, to realise a complex analysis of teaching and learning in Czech schools and to realise a series of case studies of Czech basic schools.

Pedagogical content knowledge as a key issue in curricular reform - GA ČR 406/06/ P037 (2006-2008)

The project concentrated on L. S. Shulman's concepts of pedagogical content knowledge and knowledge base for teaching. It focused on the diagnosis and analysis of pedagogical content knowledge of experienced primary school teachers. The aim of the project was to analyse and describe the features of this knowledge and the construction and development of the processes. A complex research strategy was employed that included both qualitative and quantitative methodologies (narrative interview, concept mapping, structuring cards technique, videoanalysis of teachers' acting, etc.). In the content dimension, the project aimed provide an analysis of pedagogical content knowledge of primary school teachers. In the methodological dimension, it contributed to the development of methods and techniques of investigating the pedagogical content knowledge.

The content dimension of basic school curriculum - GA ČR 406/05/0246 (2005-2007) The project aimed at the analysis of the demands on educational content, in particular on the level of the basic school leaver. The topic was examined from the point of view of the schools and also from the point of view of the society's expectations. Quantitative approaches (lesson analyses, curricular document analyses, textbook analyses and questionnaires) as well as qualitative ones (participative observation in schools and case studies) were implemented. Within the project, seminars and conferences were organised and theoretical studies, conference books and other outcomes were published. The project contributed to the clarification and specification of the basic school curriculum's function in the content and methodical dimensions.

Tacit pedagogical knowledge and the self-regulation of the process of its development - GA ČR 406/02/ 1247 (2002-2004)

The aim of this interdisciplinary project was to find the relationship between tacit and explicit pedagogical knowledge and to study the conditions of the self-regulation of their development process (with both the student teachers and in-service teachers). The qualitative methodology (non-structured observation, teacher's biography method, ethnographic interview, case studies of students and their self-reflective reports) topped up with an experiment based on quantitative research procedures were employed. The intervention that support the self-regulation of the process of the tacit pedagogical knowledge development were suggested. 


\section{Conferences and seminars}

Between 2003 and 2013, IRSE organised or co-organised a number of events that aimed to serve as opportunities for colleagues in the Czech Republic and abroad to share research ideas and also research results. Great many of these events were intended for the Czech research community, some had international implications. Some of the latter are listed below.

Internationale Tagung der Internationalen Gesellschaft für historische und systematische Schulbuchforschung - Methodenfragen in der Schulbuch- und Lehrmittelforschung

September 27-29, 2013, Faculty of Education, Masaryk University, Brno, Czech Republic

Emotions in School and Instruction: The Power of Video Studies in Investigating Teaching and Learning in the Classroom $V$

December 4-6, 2012, Friedrich-Schiller-Universität Jena, Germany

Power of Video Studies in Investigating Teaching and learning IV

November 17-21, 2010, IPN - Leibniz Institute for Science and Mathematics Education, University of Kiel, Germany

New Pathways in the Professional Development of Teachers

June 15-16 2010, Faculty of Education, Masaryk University, Brno, Czech Republic

IX. Internationale Sommerakademie Bewegung und Sport im Kontext: Themen Methoden - Daten - Analysen

May 17-21 2010, Zentrum für Sportwissenschaft und Universitätssport, Universität Wien, Austria

The power of video studies in investigating teaching and learning in the classroom III November 17-20, 2009, Faculty of Education, Masaryk University, Brno, Czech Republic

The Power of Videostudies in Teaching and Learning in Classroom II April 3-6, 2008, Fridrich-Schiller-Universität Jena, Germany

The Power of Videostudies in Teaching and Learning in Classroom I November 1-3, 2007, Faculty of Education, Masaryk University, Brno, Czech Republic

Sommerakademie VII - Neue Herausforderungen im Gesundheitsbereich an der Schule: Was kann der Sportunterricht dazu beitragen? 
90 August 20-24, 2006, Telč, Czech Republic

Foreign Language Acquisition at an Early Age

March 15, 2006, Faculty of Education, Masaryk University, Brno, Czech Republic

\section{Staff members}

Between 2003 and 2013 the following staff were members of the Institute: Josef Maňák (head of the Insitute between 2003 and 2008), Tomáš Janík (head of the Institute since 2008), Michaela Píšová, Tomáš Janko, Petr Knecht, Milan Kubiatko, Eva Minaříková, Veronika Najvarová, Petr Najvar, Karolína Pešková, František Tůma, Petr Vlček and Kateřina Vlčková. PhD students of the time included Petr Blažej, Tereza Češková, Marie Doskočilová, Libuše Ďurišová, Gabriela Hublová, Jana Chocholatá, Miroslav Janík, Tomáš Janko, Jana Jašková, Veronika Lokajíčková, Jana Lukášová, Jana Přikrylová, David Solnička, Simona Šebestová, Marek Těšík and Veronika Tománková.

\section{International cooperation}

Since 2003, IRSE has cooperated with many institutions in Germany, Austria, Slovakia and other countries. Among prominent of those were Lehrstuhl für Schulpädagogik und Didaktik, Friedrich-Schiller-Universität Jena; IPN - Leibniz-Institut für die Pädagogik der Naturwissenschaften und Mathematik an der Universität Kiel; School of Education, Technische Universität München; Interfakultärer Fachbereich Sport- und Bewegungswissenschaft an der Universität Salzburg; and National Institute for Education, Bratislava. 


\section{Outlook}

In the coming decade, IRSE will continue to strive to contribute to further development of educational research in the Czech Republic. Its activities will continute to focus into the alma mater as well as into the research community in the Czech Republic as well as abroad. Our aim is to follow our motto "better education through research" so that tangible contribution to pedagogy is made by the year 2023.

Tomáš Janík Institute for Research in School Education Faculty of Education, Masaryk University tjanik@ped.muni.cz

Petr Najvar Institute for Research in School Education Faculty of Education, Masaryk University najvar@ped.muni.cz

Marie Doskočilová Institute for Research in School Education Faculty of Education, Masaryk University 12574@mail.muni.cz 